\title{
RANCANG BANGUN APLIKASI PENGENALAN CERITA RAKYAT TIMUN MAS BERBASIS GAME 3D
}

\author{
Kholid Fathoni ${ }^{1}$, Jauari Akhmad Nur Hasim², Muhammad Zakky Fathony ${ }^{2}$, \\ Rizky Yuniar Hakkun ${ }^{1)}$, Rengga Asmara ${ }^{2}$ \\ ${ }^{1}$ Departemen Teknik Multimedia Kreatif, ${ }^{2}$ Departemen Teknik Informatika dan Komputer \\ Politeknik Elektronika Negeri Surabaya, Indonesia \\ Email : kholid@pens.ac.id, jauari@pens.ac.id,muhammadzakkyf@student.eepis-its.edu
}

\begin{abstract}
Indonesia is a country that has diverse cultures such as folklore. At this time many folklore is increasingly forgotten especially by the younger generation, one of them is Timun Mas. This raises concerns about the extinction of Timun Mas folklore as Indonesia's cultural heritage. The cause of the younger generation to forget the folklore is due to unattractive packaging, as well as the entry of various games that come from outside which can also carry the content of foreign cultures. Therefore required a media that can pack the folklore so interesting to learn by the younger generation. The author gives an idea how to package the folklore of Timun Mas so interesting by using $3 D$ gaming technology as an alternative of learning media. Folklore of Timun Mas is visualized in the game as interesting characters, appropriate gaming environment, and supported graphics and audio capabilities are sufficient. By using 3D games technology, users can play games that contain learning so that users will not feel bored. The results of this experimental study show that Timun Mas game can run on desktop devices, all 3D characters can be implemented properly. From the results of user surveys also shows that this game can serve as a learning medium, easy to use and has an attractive appearance.
\end{abstract}

Keywords: Timun Mas, Folklore, Learning Medium, 3D Game

\section{PENDAHULUAN}

Cerita rakyat adalah cerita yang berasal dari masyarakat dan berkembang dalam masyarakat pada masa lampau yang menjadi ciri khas setiap bangsa yang memiliki kultur budaya yang beraneka ragam mencakup kekayaan budaya dan sejarah yang dimiliki masing-masing bangsa. Pada umumnya, cerita rakyat mengisahkan tentang suatu kejadian di suatu tempat atau asal muasal suatu tempat. Tokoh-tokoh yang dimunculkan dalam cerita rakyat umumnya diwujudkan dalam bentuk binatang, manusia maupun yang lain.

Namun, seiring perkembangan zaman di era modern ini, generasi muda kurang tertarik untuk melestarikan cerita rakyat yang merupakan budaya bangsa Indonesia. Di samping itu, pengenalan cerita rakyat yang sebagian besar diperkenalkan melalui media buku. Hal ini mengakibatkan pelestarian cerita rakyat dianggap sebagai hal yang kuno dan membosankan.

Banyak cara yang digunakan untuk memperkenalkan budaya Indonesia khususnya cerita rakyat seperti melalui buku, website, televisi dan sebagainya. Namun bagi sebagian orang, cara ini dianggap membosankan karena cara - cara tersebut sudah banyak digunakan. Oleh karena itu, perlu dibuat sebuah metode dengan menggunakan sebuah inovasi baru untuk menarik minat generasi muda untuk mengenal cerita rakyat agar salah satu kekayaan budaya Indonesia ini tidak hilang. Keadaan seperti ini membutuhkan suatu inovasi dalam proses pengenalan cerita rakyat, salah satunya menggunakan media game. Sehingga diharapkan generasi muda tidak lupa akan cerita rakyat yang merupakan salah satu 
hasil kebudayaan yang juga menjadi identitas dari suatu bangsa. Sekarang ini sudah sangat banyak game dengan cerita modern beredar. Dengan menggabungkan antara game dengan unsur cerita rakyat didalamnya diharapkan dapat menarik minat generasi muda untuk mau mempelajari kembali cerita rakyat yang mulai memudar.

Tujuan penelitian ini adalah bagaimana membuat sebuah game pengenalan cerita rakyat, dengan mengambil salah satu tema "Timun Mas" sebagai salah satu upaya untuk menjadi solusi pelestarian cerita rakyat melalui media kreatif. Penelitian ini juga berupaya mencari suatu metode alternatif untuk menjaga budaya bangsa. Dengan game ini player diharapkan dapat bermain serta mengetahui jalan cerita dari kisah Timun Mas.

\section{BAHAN DAN METODE PENELITIAN}

\section{Penelitian Terkait}

Berikut ini adalah penelitian sebelumnya yang pernah membahas tentang cerita rakyat tradisional Indonesia.

1.Sistem Kumpulan Cerita Daerah Di Indonesia Berbasis Android (Penelitian oleh Mumpuni Widyawati - STMIK AMIKOM Yogyakarta - 2014)

Pada penelitian ini, penulis membuat sebuah aplikasi mobile, dimana aplikasi ini menampilkan informasi tentang berbagai cerita rakyat yang ada di Indonesia. aplikasi ini terdiri dari beberapa bagian utama, yaitu splash screen, menu utama, menu kumpulan cerita, menu isi cerita, menu pencarian, menu bantuan dan menu keluar. Dengan penyusunan cerita yang diurut sesuai dengan asal daerah serta adanya menu pencarian, user menjadi dimudahkan untuk mencari carita yang diinginkan mengingat aplikasi ini memuat cukup banyak judul cerita. Serta desain aplikasi yang baik akan menambah ketertarikan user dalam menggunakan aplikasi ini.
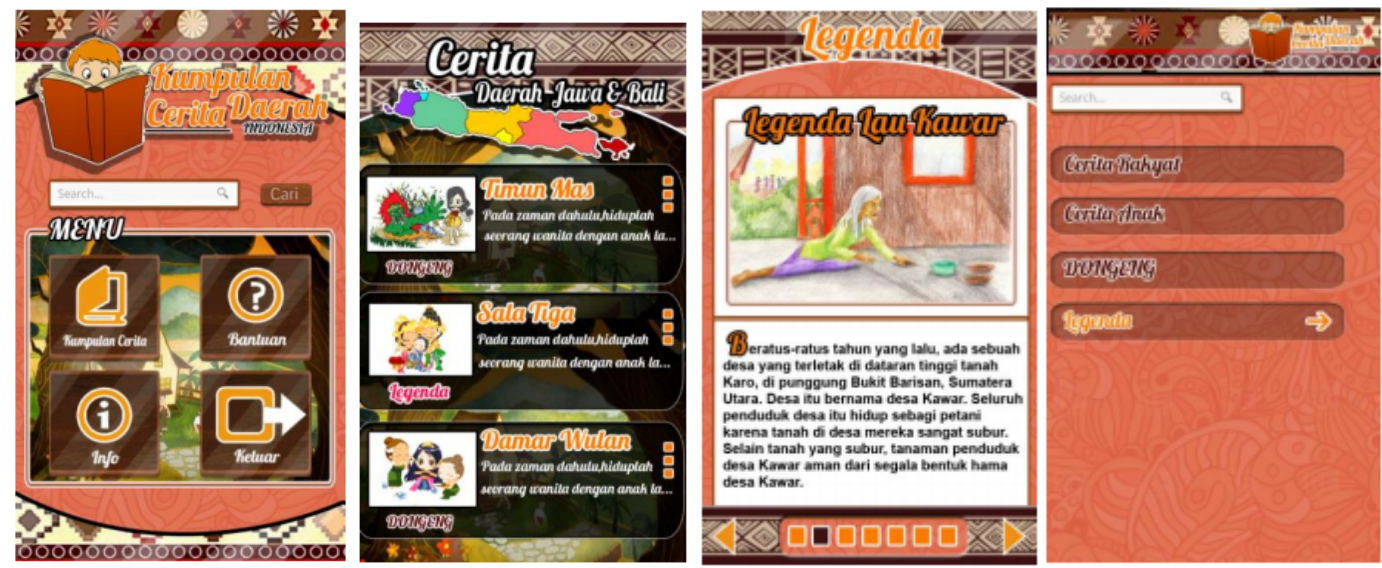

Gambar 1 Tampilan Sistem Kumpulan Cerita Daerah Di Indonesia Berbasis Android

Aplikasi ini memberikan kemudahan kepada user dalam mengenal berbagai cerita rakyat yang ada di Indonesia. karena aplikasi ini berbasis mobile aplikasi ini sangat praktis untuk dibawa kemanamana. sehingga user dapat membaca dan menikmati cerita rakyat kapanpun dan dimanapun, tanpa perlu membawa buku bacaan.

\section{Pembuatan Game Action "Timun Mas" (Penelitian dari Fiolin Theresia Sumaco - UBAYA - 2013)}

Pada penelitian ini, penulis membuat sebuah aplikasi berjenis game untuk platform desktop dan mengusung kisah "Timun Mas" sebagai alur cerita di dalam game. Game ini mempunyai genre action dan menggunakan assets 2D. Desain dari assets yang baik serta penggabungan unsur cerita rakyat dengan game akan menambah ketertarikan user dalam menggunakan aplikasi ini. game ini mempunyai beberapa fitur menu, yaitu menu mode cerita, menu mode survival, menu cara bermain, menu 
pengaturan, menu nilai tertinggi dan menu keluar. dengan adanya dua mode permainan dapat menambahkan variasi bagi user saat memainkan game ini.

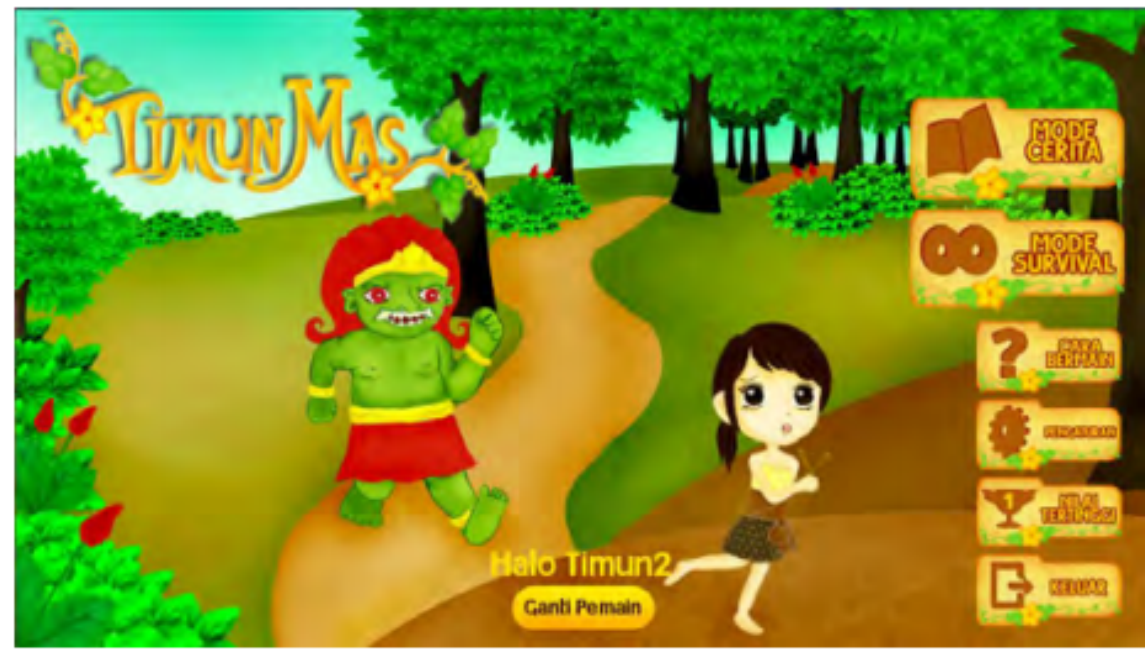

Gambar 2 Tampilan Game Action "Timun Mas”

\section{Keunikan Penelitian}

Dengan adanya permasalahan yang telah dijelaskan sebelumnya, maka penulis mengusulkan sebuah penelitian berupa game yang bertujuan untuk memperkenalkan cerita rakyat "Timun Mas". Game ini berjalan di platform desktop. Namun, dengan konsep dan fitur yang berbeda dari penelitian yang sudah ada. Game cerita rakyat "Timun Mas" ini menyajikan cerita, dimana dalam cerita tersebut karakkter - karakternya dibuat dalam bentuk animasi 3D. game ini mempunyai genre advanture. sehingga user dapat menjelajahi lingkungan di dalam game. Serta adanya musuh dan rintangan rintangan yang menghalangi user dalam menyelesaikan game, akan menjadi sebuah faktor tantangan jika user gagal saat memainkan game ini. dengan adanya fitur - fitur tersebut bertujuan agar user semakin tertarik dalam mengenal cerita daerah di Indonesia.

\section{Metode Penelitian}

Game ini merupakan game pengenalan cerita rakyat "Timun Mas" yang dijalankan pada platform desktop. Game ini merupakan game bergenre action advanture dengan kontrol yang mempunyai perspektif 3rd person, dimana user akan mengontrol karakter yang sudah disediakan sesuai dengan cerita yang ada di dalam game. Game ini menggunakan asset berupa model 3D dimana karakter - karakter dan lingkungan yang ada di dalam game ini akan disajikan dalam bentuk model 3D. Dengan digunakanya lingkungan 3D ini. user akan dapat menjelajahi lingkungan level yang ada di dalam game ini. Pada tiap level akan ada cerita pembuka dan dialog antar karakter. cerita pembuka dan dialog antar karakter ini bertujuan agar user mengerti sebab dan tujuan untuk menyelesaikan tiap level yang ada.

Pada tahap perencanaan penulis melakukan proses desain sistem, perancangan alur, skenario dan desain dari berbagai Cerita rakyat yang ada dalam Sistem. Rancangan alur sistem akan dijelaskan pada gambar 3 berikut : 


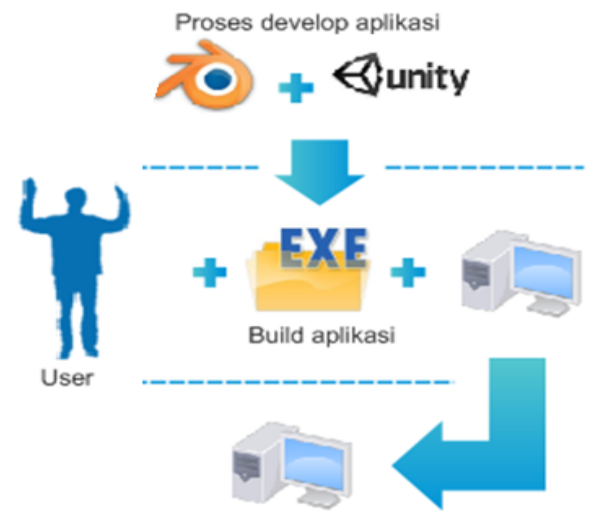

game dapat dimainkan

\section{Gambar 3 Cara Kerja Sistem}

Proses develop sistem ini terdiri dari 2 bagian yaitu pembuatan model 3D dan implementasi coding (scripting). Scripting bertujuan untuk memberikan behavior pada obyek - obyek 3D yang telah dibuat. setelah proses develop selesai maka akan dilakukan proses building sistem menjadi file executable (.exe). Terakhir adalah proses pemasangan sistem ke platform desktop sebelum akhirnya sistem dapat digunakan oleh user.

\section{Desain Level}

Game ini terbagi atas 3 level, dimana tiap level mempunyai tujuan (objective) dan tingkat kesulitan yang berbeda, namun tidak keluar dari alur cerita yang sebenarnya. Berikut ini deskripsi dari skenario level game yang akan dibuat.

\section{Level 1}

Player memainkan karakter Mbok Srini (Ibu Timun Mas). Pada level ini player akan menyusuri lingkungan game berupa hutan sebagaimana ditunjukkan gambar 4.

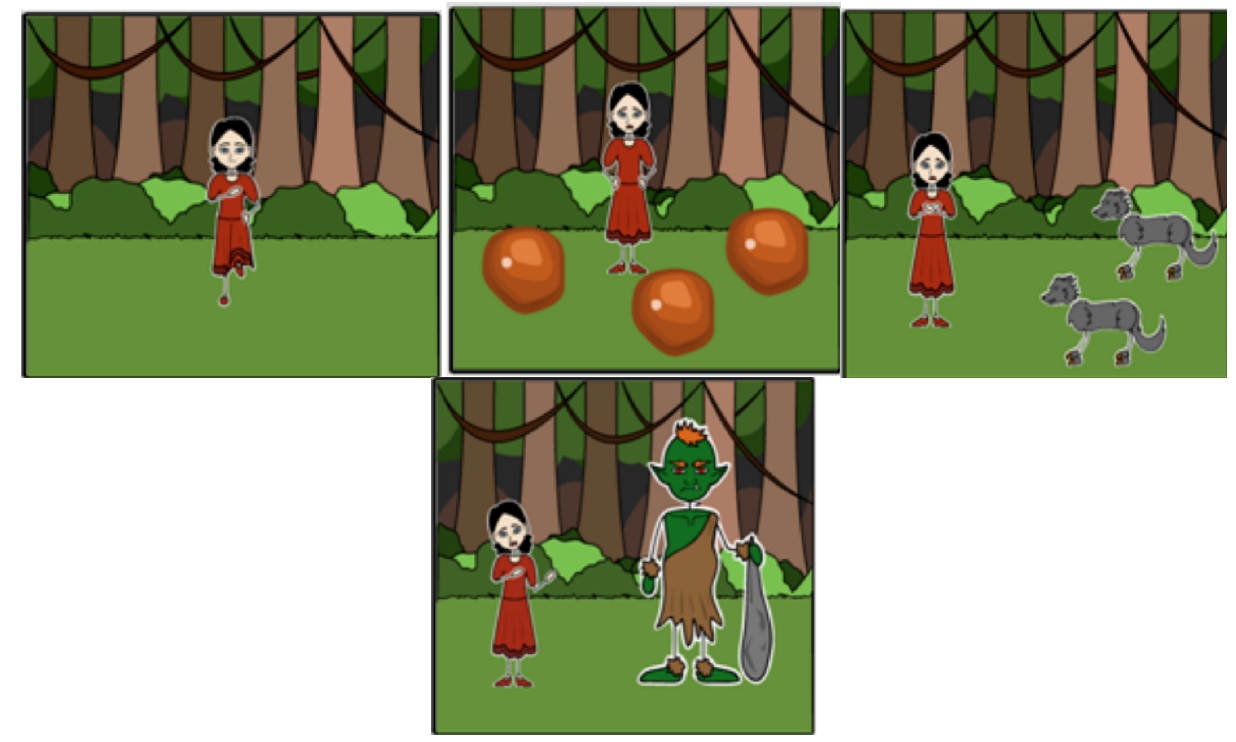

Gambar 4 Desain Level 1

Di perjalanan player akan dihadapkan dengan beberapa rintangan seperti bebatuan maupun lubang yang harus dihindari. Selain itu player juga harus melawan musuh berupa binatang buas. Akhir 
dari level satu adalah ketika player berhasil menemui Buto Ijo. Pada cerita ini ada percakapan antara Mbok Srini dan Buto Ijo.

\section{Level 2}

Pada level 2, player masih memainkan karakter Mbok Srini. Tugas player adalah merawat tanaman timun mas yang diberikan oleh Buto Ijo. Kemudian player juga harus melindungi tanaman dari serangan binatang perusak tanaman. Akhir dari level ini adalah tanaman timun telah berbuah sangat besar. Selanjutnya ada cerita dimana seorang Timun Mas lahir. Visualisasi level 2 ditunjukkan gambar 5 berikut.
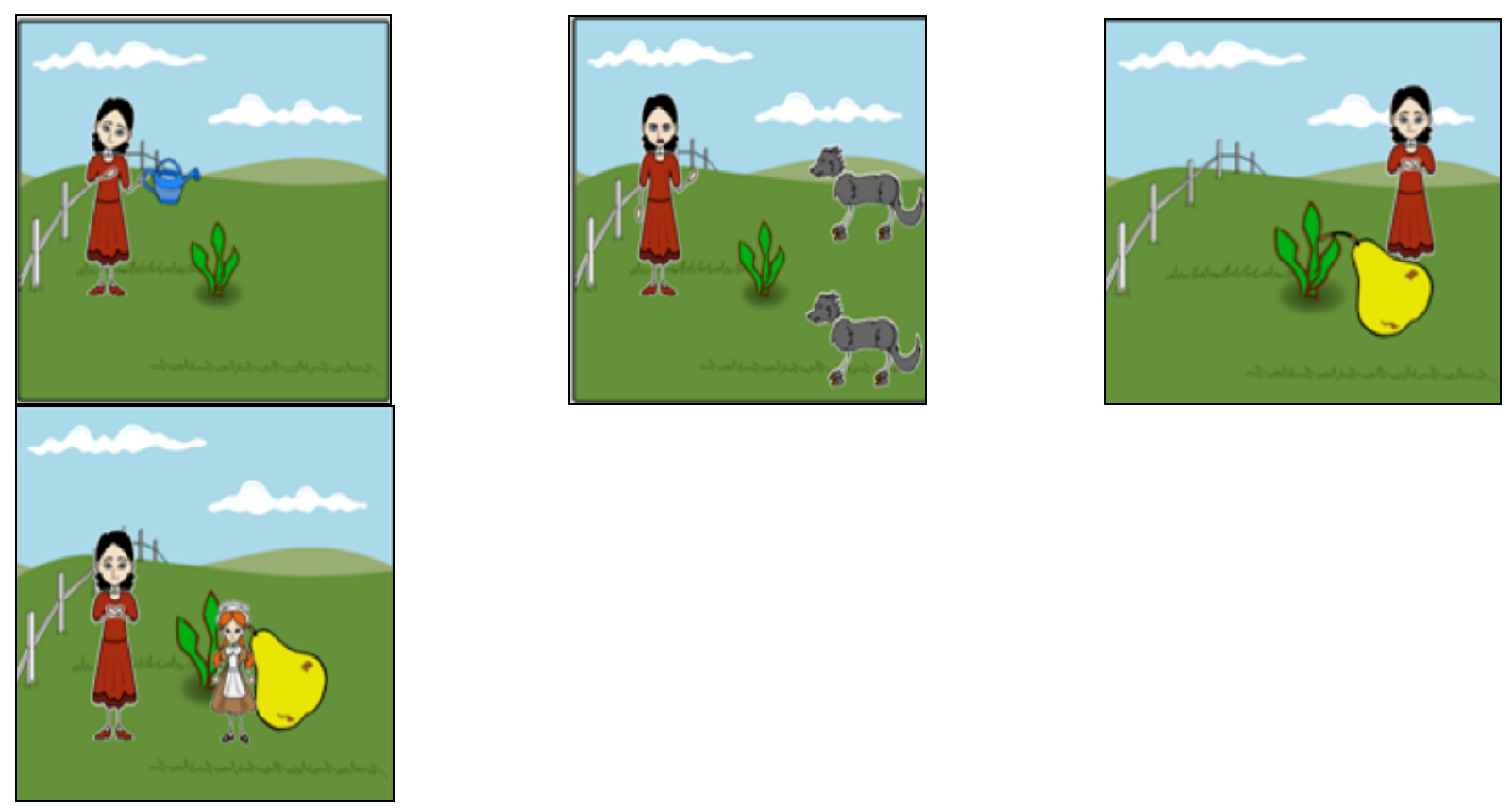

\section{Gambar 5 Desain Level 2}

\section{Level 3}

Pada level 3, player memainkan karakter Timun Mas dimana berlari menghindari kejaran Buto Ijo, yang salah satu tampilannya ditunjukkan gambar 6 berikut ini.

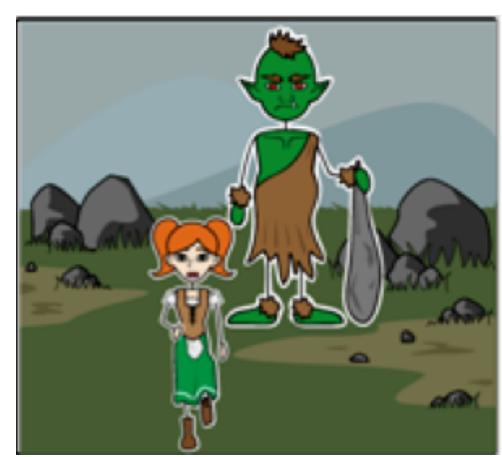

Gambar 6 Desain Level 3 


\section{HASIL DAN PEMBAHASAN}

\section{Karakter pada Game}

Dalam game terdapat dua jenis karakter yaitu karakter utama dan dua karakter tambahan. Karakter utama adalah karakter yang memang ada dan menjadi elemen utama di dalam cerita, karena karakter-karakter ini akan sangat berperan di alur jalanya cerita. Sedangkan karakter tambahan adalah karakter yang tidak ada di dalam cerita. Namun, karena sistem ini adalah sebuah game, maka karakter ini sangat membantu, dimana karakter tambahan ini berperan sebagai musuh yang menghalangi user dalam menyelesaikan game ini. sehingga game menjadi lebih menarik dan interaktif bagi user. Meskipun karakter tambahan ini disertakan di dalam game. tetapi tidak akan merubah cerita inti yang ada di dalam sistem ini.

Berikut ini beberapa karakter 3D pada game yaitu Timun Mas, Ibu Timun Mas (Mbok Srini), Buto Ijo, Babi Hutan dan Serigala.

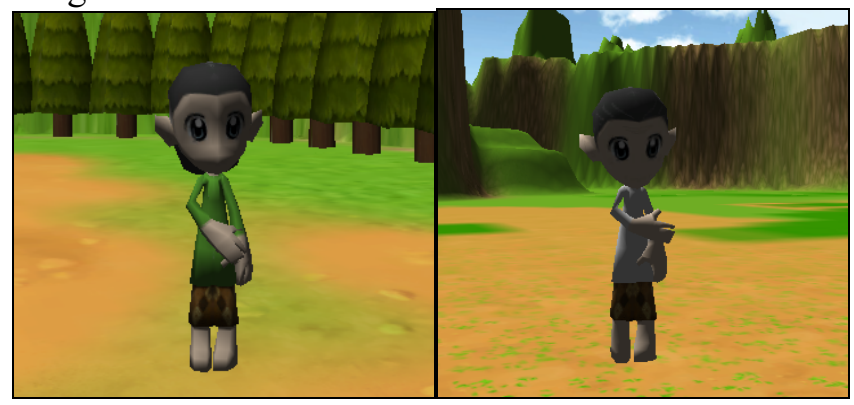

Gambar 7 Timun Mas dan Mbok Srini

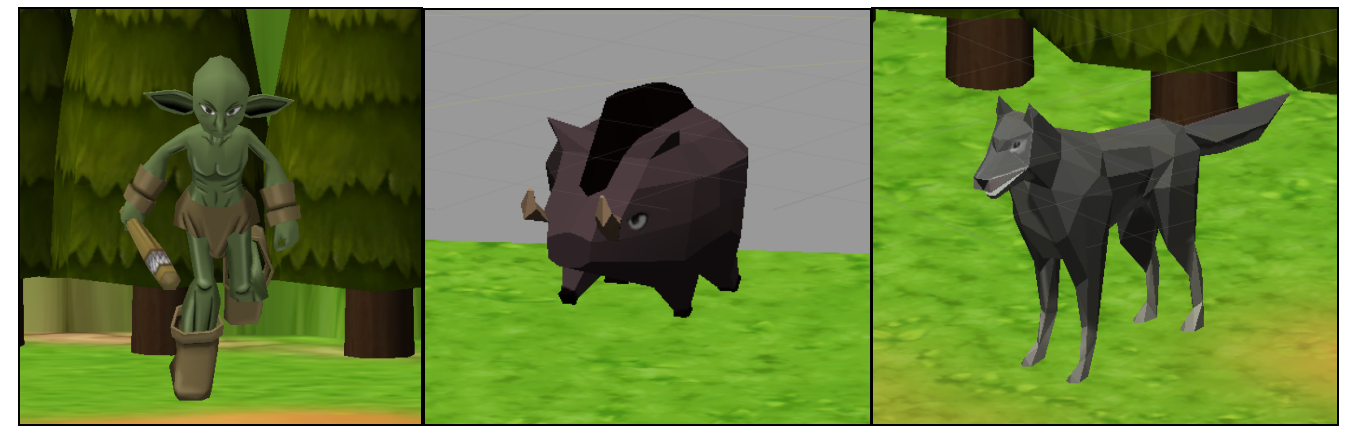

Gambar 8 Buto Ijo, Babi Hutan dan Serigala

\section{Pengujian Gameplay}

Ujicoba sistem dilakukan pada Laptop Asus VX 113D dengan resolusi 1377 x 768. Dalam ujicoba sistem ini akan dilakukan beberapa ujicoba terhadap form-form yang ada dalam aplikasi. Form yang akan diuji adalah sebagai berikut :

1. Main Menu

Ujicoba main menu dilakukan untuk memastikan main menu dapat berjalan dengan baik dan semua button bekerja dengan semestinya.

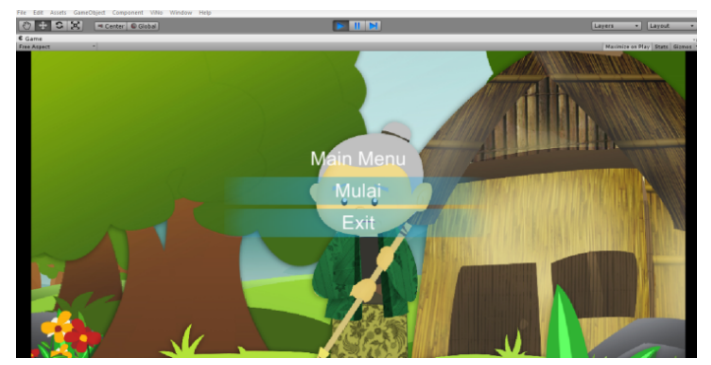

Gambar 9 Tampilan Main Menu 
2. Intro Level 1, 2 dan 3

Ujicoba dilakukan dengan mejalankan intro level 1, level 2 dan level 3. Indikator keberhasilan adalah jika button dalam form ini berjalan dengan semestinya.

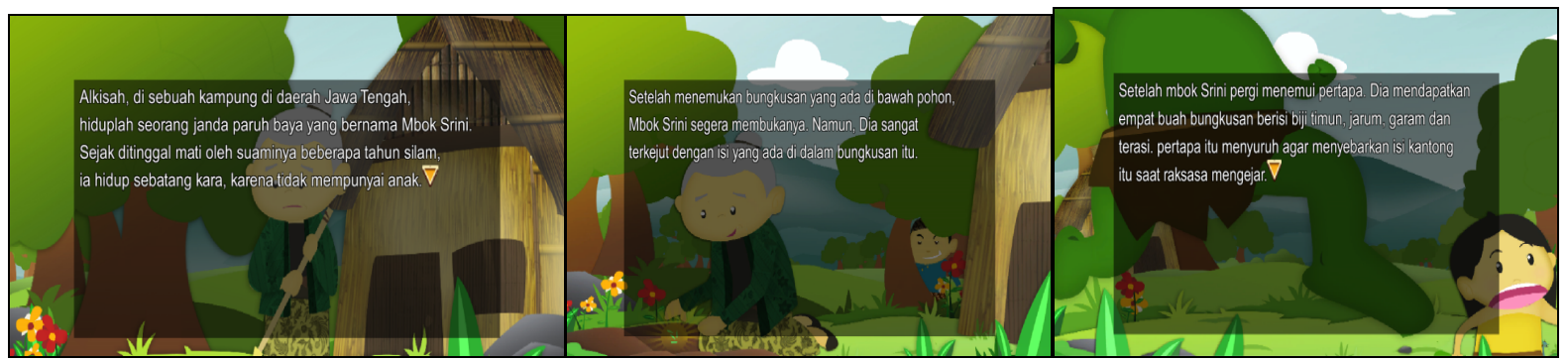

Gambar 10 Tampilan salah satu slide pada intro level 1, 2 dan 3

Hasil pengujian dapat dilihat pada gambar 10 dimana text dapat ditampilkan dengan baik dan button lanjut dapat berjalan dengan baik.

3. Playing Game pada Level 1, 2 dan 3

Ujicoba dilakukan dengan menjalankan level 1 dan memastikan semua berjalan dengan semestinya. Adapun hasil ujicoba dari level 1 dapat dilihat pada Gambar 11.

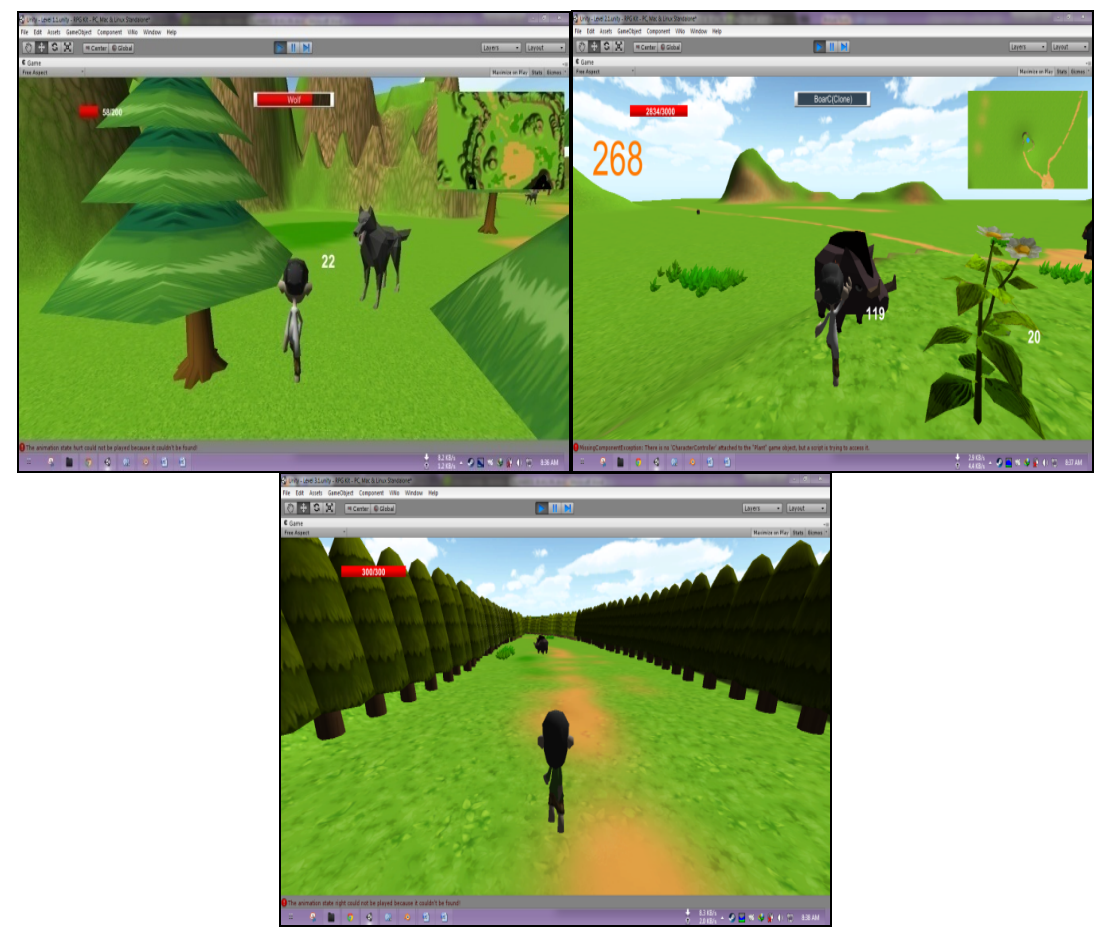

Gambar 11 Tampilan permainan level 1, 2 dan 3

Dari ujicoba yang telah dilakukan, level 1,2 dan 3 berjalan dengan baik mulai game dimulai sampai game selesai. 


\section{Analisis Pengguna}

Untuk mengetahui tingkat kepuasan user pada aplikasi ini, dibuatlah kuisioner yang berisi parameter-parameter yang merepresentasikan tingkat kepuasan dari user. Berikut ini adalah tabel hasil kuisioner :

Tabel 1 Tingkat Kepuasan Pengguna

\begin{tabular}{l|c|c|c|c|c}
\hline No & $\begin{array}{c}\text { Pengetahuan } \\
\text { tentang } \\
\text { Timun Mas }\end{array}$ & Penggunaan & Tampilan & $\begin{array}{c}\text { Model } \\
\text { 3D }\end{array}$ & Edukasi \\
\hline $\mathbf{1}$ & Tahu & Mudah & Menarik & Cukup & Membantu \\
\hline $\mathbf{2}$ & Tahu & Cukup & Menarik & Cukup & Membantu \\
\hline $\mathbf{3}$ & Tahu & Cukup & Menarik & Bagus & Membantu \\
\hline $\mathbf{4}$ & Tahu & Cukup & Menarik & Cukup & Membantu \\
\hline $\mathbf{5}$ & Tahu & Cukup & Menarik & Cukup & Membantu \\
\hline $\mathbf{6}$ & Tahu & Cukup & Tidak & Cukup & Cukup \\
\hline $\mathbf{7}$ & Tahu & Cukup & Cukup & Cukup & Cukup \\
\hline $\mathbf{8}$ & Tahu & Cukup & Menarik & Cukup & Cukup \\
\hline $\mathbf{9}$ & Tahu & Sulit & Cukup & Cukup & Membantu \\
\hline $\mathbf{1 0}$ & Tahu & Cukup & Cukup & Cukup & Cukup \\
\hline $\mathbf{1 1}$ & Tahu & Mudah & Menarik & Bagus & Cukup \\
\hline $\mathbf{1 2}$ & Tahu & Cukup & Menarik & Bagus & Membantu \\
\hline $\mathbf{1 3}$ & Tahu & Sulit & Menarik & Bagus & Membantu \\
\hline $\mathbf{1 4}$ & Tahu & Sulit & Menarik & Bagus & Cukup \\
\hline $\mathbf{1 5}$ & Tahu & Cukup & Cukup & Cukup & Membantu \\
\hline $\mathbf{1 6}$ & Tahu & Cukup & Cukup & Cukup & Cukup \\
\hline $\mathbf{1 7}$ & Tahu & Cukup & Cukup & Cukup & Cukup \\
\hline $\mathbf{1 8}$ & Tahu & Cukup & Menarik & Cukup & Membantu \\
\hline $\mathbf{1 9}$ & Tidak Tahu & Susah & Menarik & Bagus & Cukup \\
\hline $\mathbf{2 0}$ & Tahu & Susah & Cukup & Cukup & Cukup \\
\hline
\end{tabular}

Berdasarkan tabel di atas, dapat disimpulkan bahwa game ini cukup memberikan informasi tentang pengetahuan cerita adat "Timun Mas". Game ini cukup membuat para respoden penasaran kemudian tertarik untuk mencoba. karena mereka merasa game 3D yang mengangkat cerita adat sebagai alur cerita masih relatif jarang.

\section{KESIMPULAN}

Berdasarkan hasil analisis dari beberapa pengujian yang diterangkan sebelumnya, maka dapat disimpulkan sebagai berikut :

1. Semua fitur game ini dapat berjalan dengan baik pada platform desktop.

2. Performa grafik saat dijalankan sudah cukup baik hal ini karena menggunakan metode low poly dalam membuat modellingnya, sehingga tidak membutuhkan banyak resource yang memberatkan.

3. Aplikasi ini mudah digunakan, serta memiliki tampilan yang menarik bagi pengguna.

4. Aplikasi ini dapat digunakan sebagai sarana edukasi (pelestarian cerita budaya) khususnya tentang kisah Timun Mas.

\section{DAFTAR PUSTAKA}

http://www.derelictstudios.net/blitz2/

http://asia.gamespot.com/blitzkrieg-2/reviews/blitzkrieg-2-review-6141184/ 
Jurnal Nasional Teknologi Terapan, Vol. 2 No. 1 Mei 2018: 62 - 70

http://en.wikipedia.org/wiki/First_video_game (Diakses 6 Desember 2014)

T. T. Goldsmith, JR. ET. AL. 1948. Cathode-Ray Tube Amusement Device.

http://www.anneahira.com/sejarah-game.htm (Diakses 27 Oktober 20142)

http://www.gameedukasi.com/2010/12/game-timun-mas/ (Diakses 1 Januari 2015) 